\title{
Perbandingan Pengaruh Adaptasi Aspergillus niger Terakumulasi Litium Pada Proses Bioleaching
}

\author{
Cintiya Septa Hasannah *, Muhammad Fahmi Hakim, dan Azafilmi Hakiim \\ Program Studi Teknik Kimia Fakultas Teknik Universitas Singaperbangsa Karawang \\ *) Corresponding author: cintiya21@yahoo.co.id
}

(Received 29-Oct-19 • Revised 18-Nov-19•Accepted 29-Nov-2019)

\begin{abstract}
Technological development does not necessarily have an always positive impact. For example, as portable products increase, the need for batteries will increase significantly. This will increase the amount of waste battery. Consumers throw away hundreds or even millions of waste batteries each year containing toxic and corrosive substances to the environment just like that. Therefore, there needs to be a treatment to treat battery waste, one of which is to recover the metal contained in the battery. Bioleaching is a metal extraction process carried out with the help of bacteria or fungi that are able to convert metal compounds that cannot dissolve into metal sulfate compounds that can dissolve in water through biochemical reactions. In the bioleaching process, the fungus has the role of producing organic acids that are capable of dissolving metals. The purpose of this study is to determine the effect of adaptation of microorganisms on lithium to the amount of lithium accumulation and compare it with lithium accumulation without any adaptation of microorganisms. The fungus used is Aspergillus niger, and the waste battery used is a used laptop battery. The comparison can be shown from the results of lithium bioleaching with the adaptation process that is equal to $80 \%$ of leached lithium, while for the results of lithium bioleaching without the process of adaptation is only $58 \%$ leached lithium.
\end{abstract}

\begin{abstract}
Abstrak
Perkembangan teknologi tidak serta merta memberikan dampak yang selalu positif. Sebagai contoh, seiring meningkatnya produk-produk portable maka kebutuhan baterai akan meningkat secara signifikan. Hal tersebut justru akan menambah jumlah limbah baterai. Konsumen membuang ratusan bahkan jutaan limbah baterai pertahunnya yang mengandung bahan beracun dan korosif ke lingkungan begitu saja. Oleh karena itu, perlu ada treatment untuk mengolah limbah baterai, salah satunya adalah dengan merecovery logam yang terkandung dalam baterai. Bioleaching merupakan suatu proses ekstraksi logam yang dilakukan dengan bantuan bakteri atau jamur yang mampu mengubah senyawa logam yang tidak dapat larut menjadi senyawa logam yang dapat larut dalam air melalui reaksi biokimia. Pada Proses bioleaching, jamur berperan menghasilkan asam organik yang mampu melarutkan logam. Tujuan penelitian ini adalah mengetahui pengaruh adaptasi mikroorganisme pada litium terhadap jumlah akumulasi litium dan membandingkannya dengan akumulasi litium tanpa adanya adaptasi mikroorganisme. Jamur yang digunakan adalah Aspergillus niger dan limbah baterai yang digunakan adalah baterai laptop bekas. Perbandingan dapat ditunjukkan dari hasil bioleaching litium dengan proses adaptasi yaitu sebesar $80 \%$ litium terleaching, sedangkan untuk hasil bioleaching litium tanpa proses adaptasi hanya sebesar 58\% litium terleaching.
\end{abstract}

Keywords: Aspergilus niger, bioleaching, used batteries 


\section{PENDAHULUAN}

Perkembangan teknologi tidak serta merta memberikan dampak yang selalu positif. Sebagai contoh, seiring meningkatnya produk-produk portable maka kebutuhan akan baterai Litium Ion Battery (LIB) meningkat secara signifikan. Peningkatan tersebut sebanding dengan penambahan jumlah limbah baterai LIB. Konsumen membuang ratusan bahkan jutaan limbah baterai pertahunnya yang mengandung bahan beracun dan korosif ke lingkungan begitu saja. Padahal di dalamnya terdapat logam yang masih bisa dimanfaatkan kembali salah satunya adalah lithium. Keberadaan lithium di alam bukan sebagai unsur bebas akan tetapi tergabung membentuk senyawa ionik. Sehingga perolehan litium dari alam dilakukan melalui proses yang sukar dan biaya yang cenderung mahal. Selain itu, logam lain yang terdapat dalam baterai adalah cobalt. Oleh karena itu, perlu adanya pemanfaatan kembali limbah baterai, salah satunya adalah dengan merecovery logam yang terkandung dalam baterai.

Proses recovery logam menggunakan teknik leaching dengan prinsip kerja yaitu pelarut akan melarutkan sebagian bahan padatan sehingga bahan pelarut yang diinginkan diperoleh setelah itu dilakukan proses pemisahan larutan yang terbentuk dari padatan sisa [1]. Kebanyakan proses leaching dilakukan dengan menggunakan asam kuat sehingga dapat menimbulkan ancaman terhadap lingkungan (limbah berbahaya) [2]. Teknik lainnya untuk leaching logam yaitu secara bioleaching. Proses ini tentunya sangat bergantung dengan adanya mikroorganisme salah satunya adalah jamur (fungi). Ekstraksi pada jamur dapat terjadi dengan menghasilkan asam organik yang dapat membentuk chelate pada logam [3]. Asam organik yang dihasilkan oleh Aspergillus niger dapat melarutkan $\mathrm{Ni}, \mathrm{Cu}, \mathrm{Mn}, \mathrm{Li}, \mathrm{Co}$ dan Al pada LIB [4]. Aspergillus niger dapat tumbuh dengan cepat, oleh karena itu Aspergillus niger banyak digunakan secara komersial dalam produksi asam sitrat, asam glukonat, dan pembuatan enzim seperti amilase, pektinase, amiloglukosidase dan selulase [5]. Asam yang dihasilkan jamur berperan menggantikan asam kuat buatan yang digunakan pada proses leaching secara konvensional. Oleh karena itu proses bioleaching dinilai lebih ramah lingkungan dan diharapkan memiliki selektivitas yang lebih baik daripada cara-cara konvensional.

Pada penelitian sebelumnya yang dilakukan di dalam [6], telah menguji kemampuan asam sitrat organik yang diproduksi oleh Aspergillus niger untuk leaching logam litium dan cobalt pada baterai bekas yang telah di proses menjadi $\mathrm{LiCoO}_{2}$. Asam Sitrat merupakan asam organik yang lemah dan reaksinya dengan $\mathrm{LiCoO}_{2}$ adalah sebagai berikut [6]:

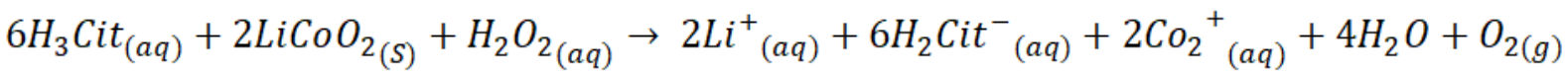

$$
\begin{aligned}
& 6 \mathrm{H}_{2} \mathrm{Cit}_{(a q)}^{-}+2 \mathrm{LiCoO}_{2(\mathrm{~S})}+\mathrm{H}_{2} \mathrm{O}_{2(a q)} \rightarrow 2 \mathrm{Li}^{+}{ }_{(a q)}+6 \mathrm{HCit}_{2}{ }_{(a q)}^{-}+2 \mathrm{Co}_{2}{ }_{(a q)}^{+}+4 \mathrm{H}_{2} \mathrm{O}+\mathrm{O}_{2(g)} \\
& 6 \mathrm{HCit}_{2}{ }_{(a q)}^{-}+2 \mathrm{LiCoO}_{2(S)}+\mathrm{H}_{2} \mathrm{O}_{2(a q)} \rightarrow 2 \mathrm{Li}^{+}{ }_{(a q)}+6 \mathrm{Cit}_{3}{ }_{(a q)}^{-}+2 \mathrm{Co}_{2}{ }_{(a q)}^{+}+4 \mathrm{H}_{2} \mathrm{O}+\mathrm{O}_{2(g)}
\end{aligned}
$$

Dari reaksi di atas dapat dilihat bahwa penambahan reduktan mampu membantu terjadinya reaksi, untuk reaksi pertama adalah reaksi leaching primer dimana Co tereduksi dari Co (III) menjadi Co (II). Namun belum ada penelitian tentang pengaruh penambahan reduktan terhadap proses leaching Li dari limbah dengan asam sitrat organik [6]. Pada reaksi leaching di atas, logam litium dan kobalt di leaching dalam bentuk $\mathrm{Co}\left(\mathrm{C}_{6} \mathrm{H}_{7} \mathrm{O}_{7}\right)_{2}, \mathrm{Li}\left(\mathrm{C}_{6} \mathrm{H}_{7} \mathrm{O}_{7}\right), \mathrm{Co}^{2+}$ dan $\mathrm{Li}^{+}$. Residu yang terbentuk adalah $\mathrm{Co}_{3} \mathrm{O}_{4}$ namun tidak dapat dilucuti kembali karena $\mathrm{Co}_{3} \mathrm{O}_{4}$ tidak larut sempurna dalam asam sitrat [8]. 
Beberapa penelitian terdahulu yang hampir berkaitan dengan penelitian ini yaitu di tahun 2012, penelitian mengenai bioleaching katalis hydrotreating oleh Acidophilic thermophile Acidianus brierleyi dilakukan di dalam [8]. Hasil dari penelitiannya yaitu proses decoking katalis mampu menghilangkan pengotor dan memperbesar luas permukaan sehingga logam sulfida mampu teroksidasi dan kelarutan logam pada mikroorganisme mnjadi efektif. Selain itu, penelitian di dalam [4] di tahun 2016 meneliti tentang pengambilan litium dari LIB bekas dengan cara leaching menggunakan asam organik yang optimal diproduksi oleh Aspergilus niger, dimana berhasil memproduksi litium pada kondisi optimal yaitu $\mathrm{pH}$, kandungan sukrosa dan inokulum masing-masing sebesar $116.90(\mathrm{~g} / \mathrm{L})$ dan $3.45 \%\left(\mathrm{v} \mathrm{v}^{-1}\right)$.

Berdasarkan studi pustaka diketahui beberapa jamur mampu mengakumulasi logam pada proses bioleaching. Perbedaan penelitian ini dengan penelitian sebelumnya adalah melakukan treatment terhadap mikroorganisme yaitu jamur Aspergilus niger dengan adaptasi terhadap logam sebelum proses bioleaching kemudian membandingkan hasil bioleaching menggunakan jamur Aspergilus niger yang tidak diadaptasi logam.

\section{METODE PENELITIAN}

\section{Bahan dan Alat Penelitian}

Penelitian ini menggunakan bahan yaitu jamur Aspergilus niger dengan media cair jamur terdiri dari ekstrak ragi, ekstrak malt, glukosa dan deionized water serta potato dextrox agar (PDA) sebagai media padat jamur. Bahan kimia pendukung antara lain: serbuk baterai digunakan untuk adaptasi jamur dan proses leaching, $\mathrm{HCl} 37 \%$ dan $\mathrm{NAOH}$ pellets digunakan untuk mengatur $\mathrm{pH}$ dan analisis titrasi dan garam dapur digunakan untuk menghilangkan muatan pada baterai bekas laptop. Alat yang digunakan petridisk, erlenmeyer, centrifuge, beker glass dan autoclave.

\section{Tahapan Penelitian}

\section{Preparasi LIB Bekas}

Baterai laptop merek Acer diperoleh dari salah satu toko service laptop di Karawang, dismantling dengan menggunakan tang dan obeng untuk membuka lapisan luar dari silindersilinder LIB. Agar lebih aman untuk proses dismantling selanjutnya, muatan dalam LIB dihilangkan dengan cara merendam silinder LIB tersebut larutan $\mathrm{NaCl}$ (dibuat dari garam dapur padat merk Swallow) dengan konsentrasi $10 \mathrm{~g} / \mathrm{L}$ selama 1 jam. Komponen LIB yang berupa lembaran diperoleh dengan membuka manual logam pelindung silinder LIB dengan menggunakan tang dan obeng. Bagian katoda $\left(\mathrm{LiCoO}_{2}\right)$ dipilih kemudian dipisahkan dari lembaran aluminium dengan cara digerus manual [9].

\section{Kulturisasi Jamur}

Proses ini menggunakan media terdiri dari $4 \mathrm{~g} / \mathrm{L}$ ekstrak ragi, $10 \mathrm{~g} / \mathrm{L}$ ekstrak malt dan 4 $\mathrm{g} / \mathrm{L}$ glukosa. Media tersebut dilarutkan dalam deionized water. Kemudian media dipanaskan /sterilisasi menggunakan autoclave selama 45 menit dengan suhu $80^{\circ} \mathrm{C}$. Setelah media cair dingin, jamur diinokulasi ke media dan diaduk terus menerus dengan kecepatan $120 \mathrm{rpm}$ selama 72 jam pada suhu $30^{\circ} \mathrm{C}$. Selanjutnya mikrooganisme dicentrifuge dengan kecepatan $3000 \mathrm{rpm}$ dan dicuci dengan deionized water untuk dikulturisasi pada media padat. 


\section{Penentuan Waktu Optimum Produksi Asam Organik}

Sampel jamur Aspergilus niger ditumbuhkan pada media cair dan diaduk secara terus menerus dengan kecepatan $120 \mathrm{rpm}$ pada suhu $30^{\circ} \mathrm{C}$. Setiap 2 hari, kultur cair tersebut diambil sebanyak $5 \mathrm{~mL}$ untuk dititrasi dengan $\mathrm{NaOH} 0.1 \mathrm{~N}$ hingga ditemukan waktu dengan kandungan asam total terbesar.

\section{Proses Adaptasi Jamur}

Jamur yang telah dikultur pada media cair, dipisahkan dengan asam metaboliknya dengan menggunakan centrifuge. Jamur kemudian dicampur dengan serbuk baterai sebanyak $(2,4,6,8,10) \mathrm{mg}$ yang telah di campurkan dengan aquadest dan diinkubasi selama 1 jam. Jamur kemudian diambil dari cairannya dengan menggunakan centrifuge untuk ditumbuhkan pada media padat.

\section{Proses Bioleaching}

Proses ini dilakukan menggunakan jamur yang sudah diadaptasi dengan $\mathrm{LiCl}$ dan jamur tanpa adaptasi. Proses diawali dengan memasukan jamur pada media cair dan disesuaikan dengan waktu optimum jamur tersebut memproduksi asam organik kemudian diinkubasi selama 5 jam. Setiap 1 jam kultul cair diambil sebanyak $5 \mathrm{~mL}$ untuk diukur kandungan logam Li nya untuk mengetahui akumulasi Li oleh jamur dengan menggunakan inductively coupled plasma (ICP).

Ringkasan metode dapat dilihat pada Gambar 1. 


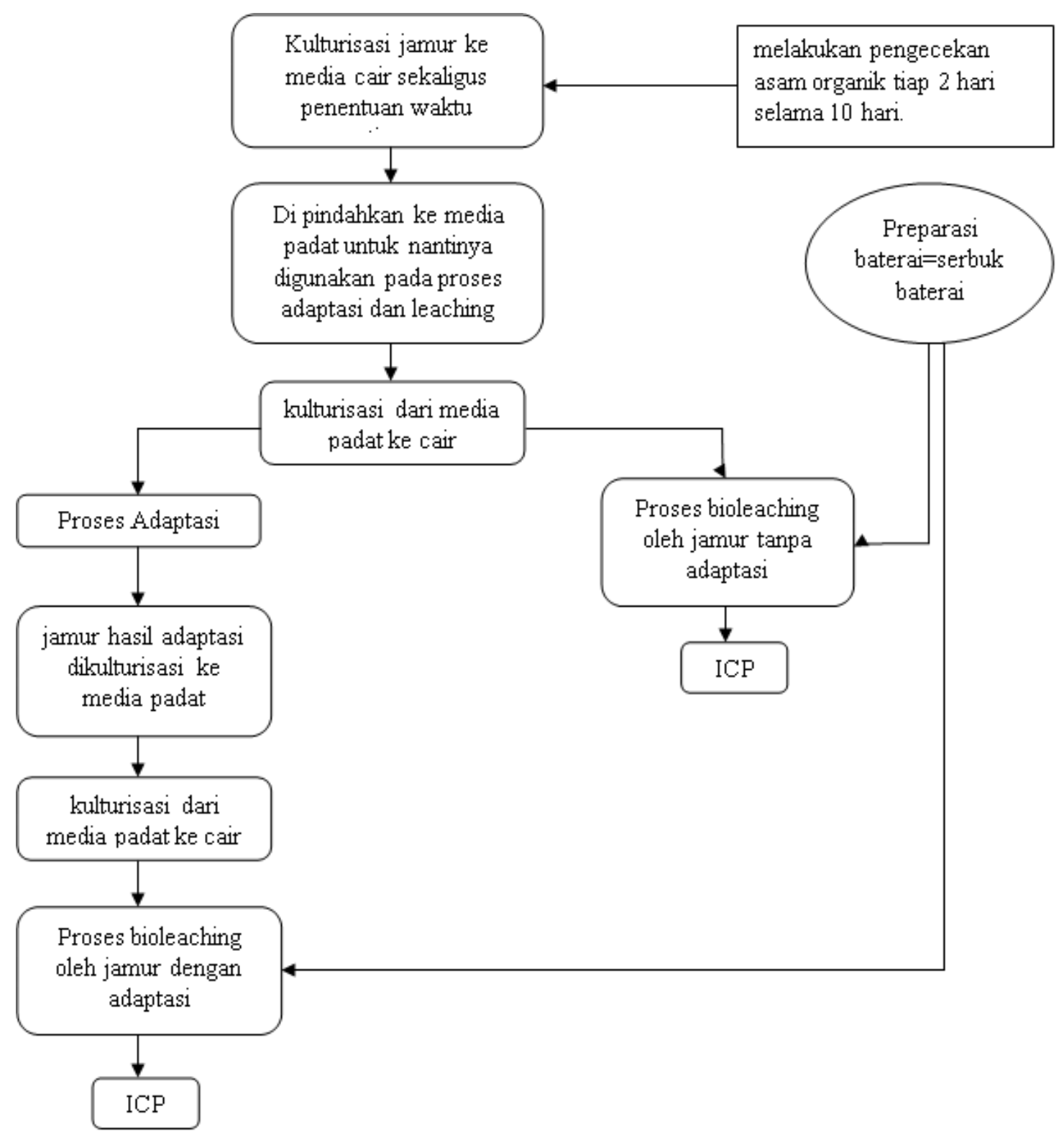

Gambar 1. Metode Penelitian

\section{Prosedur Analisa Sampel}

\section{Prosedur Jumlah Asam}

Perolehan asam total berdasarkan waktu inkubasi selama 10 hari. Setiap dua hari, sampel diukur pHnya kemudian $10 \mathrm{~mL}$ dari sampel diambil dan dianalisa jumlah asam dengan titrasi menggunakan $\mathrm{NaOH} 0.1 \mathrm{M}$. Sampel yang memiliki jumlah asam maksimal selanjutnya dipilih untuk proses adaptasi dan bioleaching.

\section{Litium Terakumulasi}

Sampel adaptasi dan sampel bioleaching baik dengan Aspergilus niger yang diadaptasi ataupun tidak diambil sebanyak $1 \mathrm{~mL}$ kemudian diencerkan dengan sterilized 
aquadest dan dihomogenisasi untuk diambil fitratnya dan dianalisis menggunakan Inductively Coupled Plasma (ICP).

\section{HASIL DAN PEMBAHASAN}

\section{Produksi Asam Organik Maksimum}

Jamur Aspergilus niger diinkubasi pada media cair selama 10 hari dan setiap 2 hari dilakukan pengecekan $\mathrm{pH}$ dan jumlah asam yang dihasilkan dengan proses titrasi. Jamur yang mampu menghasilkan jumlah asam dengan konsentrasi maksimum merupakan waktu optimum untuk proses bioleaching.

Tabel 1. pH Rata- rata

\begin{tabular}{cc}
\hline Hari & $\mathrm{pH}$ \\
\hline 2 & 4.2 \\
4 & 4.7 \\
6 & 5 \\
8 & 6 \\
10 & 6.8 \\
\hline
\end{tabular}

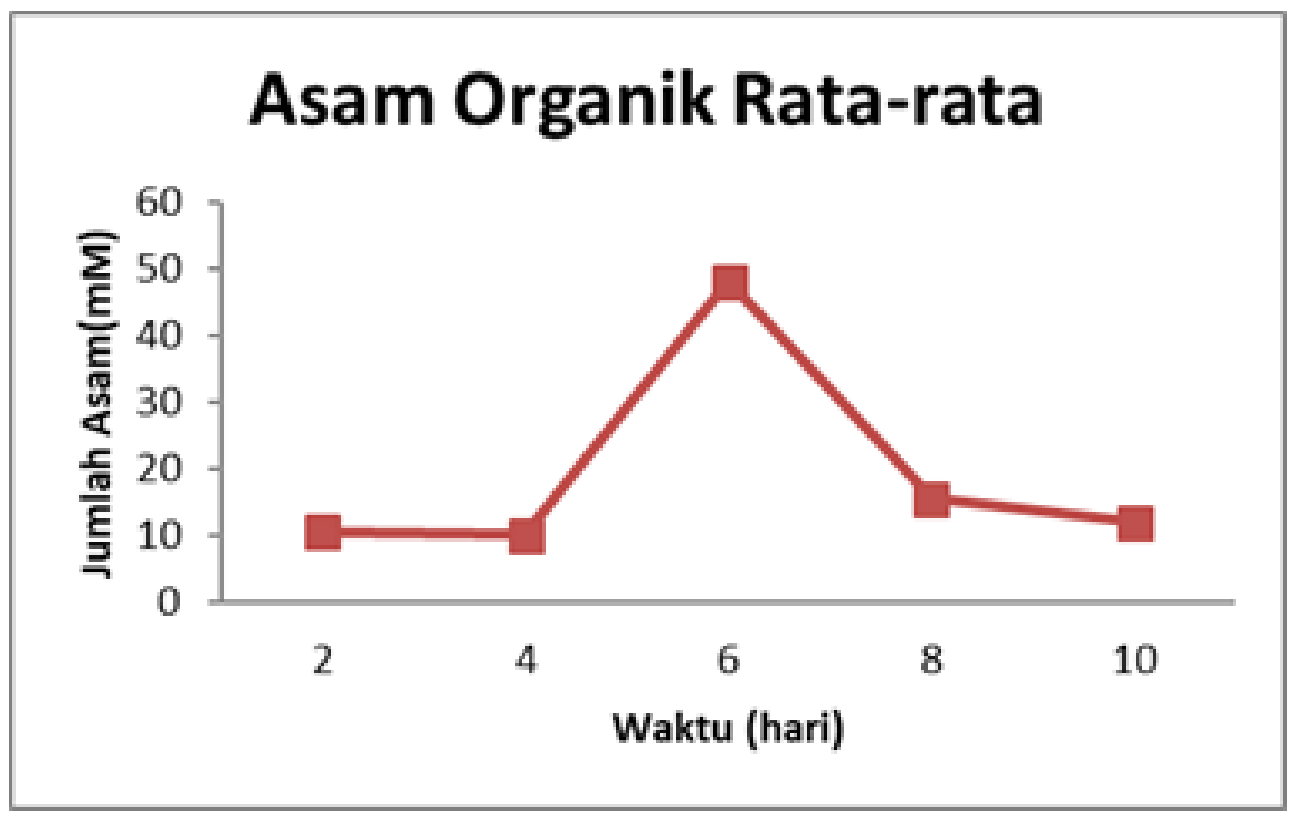

Gambar 2. Waktu Optimum Jamur Memproduksi Asam

Tabel 1 menunjukkan pH sampel yang diuji setiap 2 hari. Semakin lama waktu inkubasi maka $\mathrm{pH}$ sampel semakin meningkat. Selanjutnya Gambar 2, merupakan Aspergilus niger yang diinkubasi pada media cair selama 10 hari, dan dilakukan pengulangan sebanyak 3 kali untuk mengetahui asam organik rata-rata. Berdasarkan Gambar 2, terjadi pelonjakan konsentrasi asam maksimum dihari keenam sebesar $48 \mathrm{mM}$ dan penurunan di hari berikutnya. Peningkatan $\mathrm{pH}$ dan penurunan konsentrasi asam dapat terjadi karena jamur menyerap kembali jumlah asam yang telah dihasilkan sebagai sumber karbon karena sumber 
makanan yang semakin menipis pada media cair dan semakin lama jamur akan mati [4][10]. Hasil tahap ini kemudian digunakan untuk inkubasi jamur selama 6 hari pada saat proses bioleaching.

\section{Bioleaching dengan Proses Adaptasi}

Jamur yang telah melalui tahap adaptasi dengan serbuk baterai ditumbuhkan pada media padat untuk kemudian digunakan pada proses bioeaching. Proses bioleaching dilakukan dengan menginkubasi jamur di media cair selama 6 hari, setelah itu serbuk baterai dimasukkan sebanyak $(2,4,6,8,10) \mathrm{mg}$ ke campuran asam organik dan jamur tersebut selama 24 jam. Selanjutnya, sampel dianalisis untuk mengetahui kandungan logam litiumnya.

Tabel 2. Hasil Adaptasi Aspergilus niger dengan Serbuk Baterai

\begin{tabular}{cc}
\hline \multirow{2}{*}{ Sampel } & $\begin{array}{c}\text { Rata-rata Li terakumulasi } \\
(\%)\end{array}$ \\
\hline Ad $2 \mathrm{mg}$ & 2.6 \\
Ad $4 \mathrm{mg}$ & 5.2 \\
Ad $6 \mathrm{mg}$ & 5.3 \\
Ad $8 \mathrm{mg}$ & 6.6 \\
Ad $10 \mathrm{mg}$ & 41.2 \\
\hline
\end{tabular}

Tabel 2 menunjukan hasil dari proses adaptasi jamur dengan variasi berat serbuk baterai. Hasil dapat dilihat dari rata-rata litium yang terakumulasi oleh jamur. Semakin berat variasi serbuk baterai maka akumulasi litium juga semakin besar. Selain itu, jamur mampu bertahan dalam lingkungan dengan konsentrasi logam yang tinggi. Selanjutnya jamur dari hasil adaptasi dengan berat serbuk baterai $8 \mathrm{mg}$ dan $10 \mathrm{mg}$ dikulturisasi pada media padat untuk nantinya digunakan pada proses bioleaching.

\section{Proses Bioleaching}

Bioleaching dilakukan dengan campuran asam organik dan jamur dengan atau tanpa adaptasi. Sebelumnya Aspergilus niger ditumbuhkan pada media cair dan diinkubasi berdasarkan waktu optimum yaitu 6 hari, kemudian serbuk baterai dimasukan dan diinkubasi selama 24 jam. Hasil ditampilkan pada Gambar 3 dan 4. 


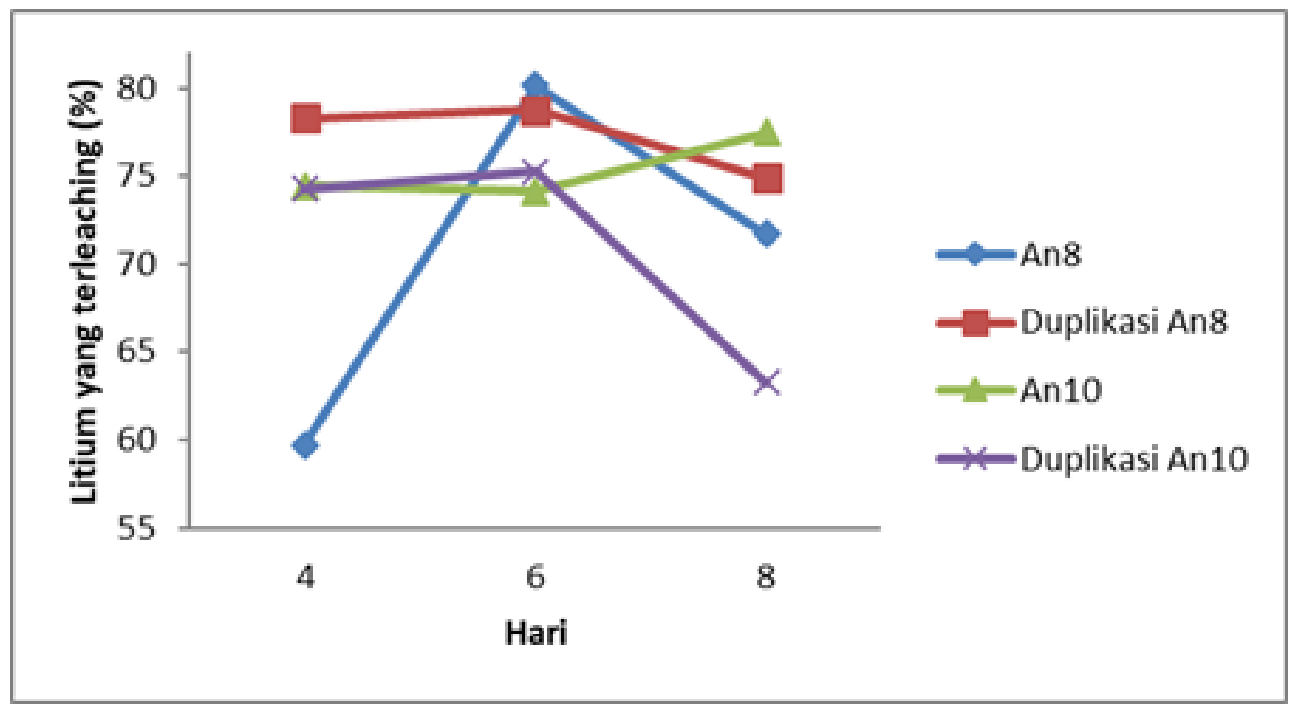

Gambar 3. Bioleaching dengan Jamur yang Diadaptasi

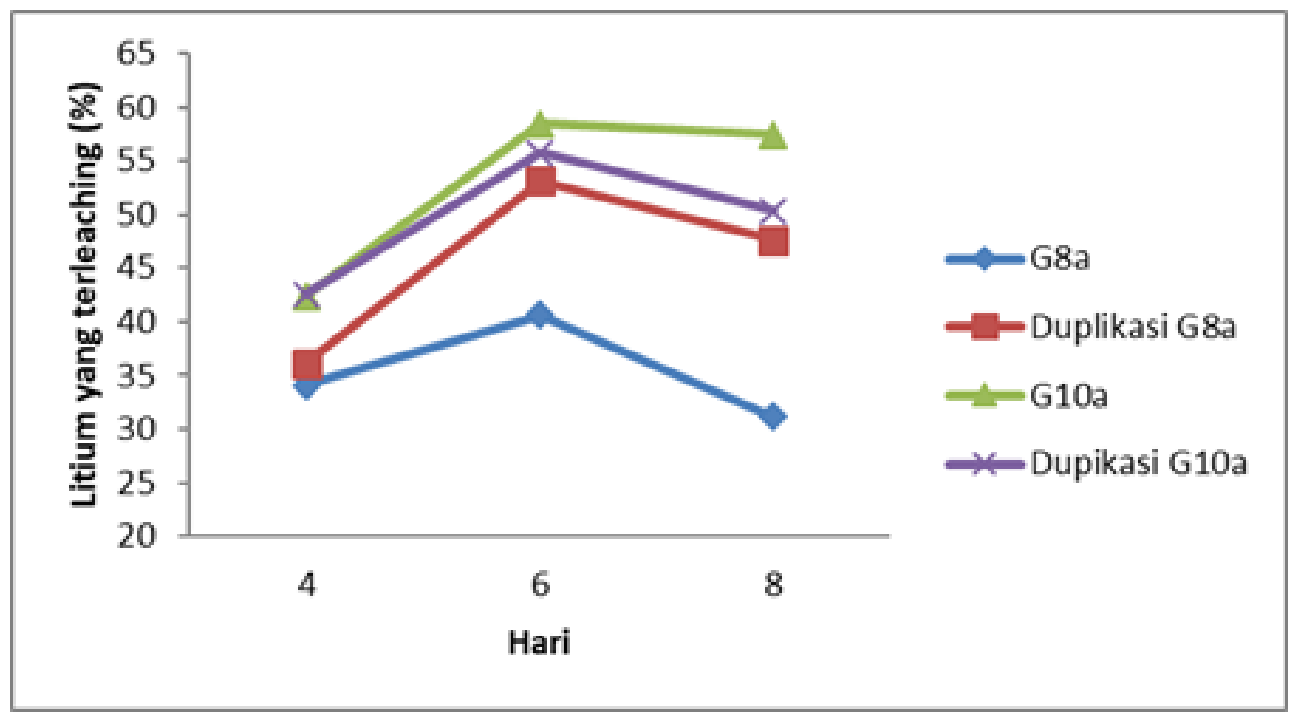

Gambar 4. Bioleaching dengan Jamur Tanpa Adaptasi

Dari grafik pada Gambar 3 menunjukan hasil leaching litium oleh jamur yang sebelumnya diadaptasi ke lingkungan yang memiliki konsentrasi logam tinggi. Hal tersebut bertujuan agar jamur senantiasa lebih tahan pada konsentrasi logam yang tinggi dan untuk melatih kecenderungan jamur untuk meleaching litium lebih banyak daripada logam lain yang ada pada serbuk baterai. Sampel An8 merupakan jamur yang diadaptasi dengan berat serbuk baterai $8 \mathrm{mg}$, sedangkan sampel An10 diadaptasi dengan berat baterai $10 \mathrm{mg}$. Masing-masing sampel diduplikasi yaitu sampel duplikasi An8 dan sampel duplikasi An10.

Berdasarkan Gambar 3, terdapat pelonjakan persentase litium yang terleaching pada hari ke 6 dan penurunan dihari selanjutnya kecuali sampel An10. Pelonjakan tersebut berkaitan dengan asam organik yang digunakan untuk proses leaching, dimana pada hari ke enam merupakan waktu optimum jamur menghasilkan asam organik. Banyaknya asam yang dihasilkan membuat litium yang terleaching juga semakin banyak. Kemudian sampel mengalami penurunan persentase karena asam organik yang semakin sedikit dan jamur yang semakin menurun nutrien pada medianya, sehingga jamur menjadikan asam organik dan 
serbuk baterai sebagai sumber nutrien sampai akhirnya mati. Namun pada sampel An10 pada hari ke 8 persentase masih terus meningkat. Hal tersebut dapat terjadi apabila kondisi substrat masih mencukupi untuk jamur melakukan metabolisme sehingga asam organik masih terus dihasilkan. Terlihat dari rentang perlonjakan persentase yang tidak terlalu jauh sehingga asam organik masih tersedia dan terus meningkatkan leaching terhadap litium.

Kecenderungan yang sama dapat dilihat dari Gambar 4 yaitu grafik yang menunjukkan proses leaching litium tanpa adaptasi yaitu terjadi pelonjakan persentase litium yang terleaching pada hari ke 6 , setelah itu mengalami penurunan pada hari selanjutnya. Bedanya untuk proses tanpa adaptasi, litium yang terleaching lebih sedikit dibandingkan dengan jamur yang dilakukan proses adaptasi terlebih dahulu. Hal ini membuktikan bahwa jamur dapat diatur ketahanannya terhadap logam dengan konsentrasi tinggi, dan memungkinkan jamur dapat diatur selektivitasnya terhadap logam yang ingin diambil atau diekstrak pada proses bioleaching.

\section{KESIMPULAN}

Berdasarkan penelitian ini dapat disimpulkan bahwa proses bioleaching dengan bantuan jamur Aspergilus niger membutuhkan waktu optimum untuk menghasilkan asam organik selama 6 hari. Waktu tersebut menjadi acuan pada proses bioleaching dan hasilnya menunjukkan bahwa proses bioleaching dengan adanya tahapan adaptasi jamur terhadap logam terlebih dahulu akan menghasilkan persen litium yang terleaching lebih besar yaitu sebesar $80 \%$ jika dibandingkan dengan jamur tanpa adaptasi yang hanya sekitar 58\%. Selain itu jamur lebih tahan terhadap kondisi ektrim dengan konsentrasi logam yang tinggi dan selektivitas jamur terhadap logam yang ingin diekstrak dapat diatur dengan proses adaptasi ini.

\section{DAFTAR PUSTAKA}

[1] F. Anjum, M. Shahid and A. Akcil, "Biohydrometallurgy techniques of low grade ores: A review on black shale," Hydrometallurgy, Vols. 117-118, pp. 1-12, 2012.

[2] D. Pant, D. Joshi, M. K. Upreti and R. K. Kotnala, "Chemical and biological extraction of metals present in E waste: A hybrid technology," Waste Management, vol. 32, no. 5, pp. 979-990, 2012.

[3] Bhalerao, "Bioleaching: An Economic Alternative for the Mining Industry: A Review," Biosci., vol. 1, pp. 67-72, 2011.

[4] N. Bahaloo-Horeh and S. M. Mousavi, "Enhanced recovery of valuable metals from spent lithium-ion batteries through optimization of organic acids produced by Aspergillus niger," Waste Management, vol. 60, pp. 666-679, 2017.

[5] B. Wu, Y. Ren and N. Li, "LiFePO4 Cathode Material," in Electric Vehicles - The Benefits and Barriers, Turkey, Sakarya University, 2011.

[6] L. Li, J. Ge, F. Wu, R. Chen, S. Chen and B. Wu, "Recovery of cobalt and lithium from spent lithium ion batteries using organic citric acid as leachant," Journal of hazardous materials, vol. 176, no. 1-3, pp. 288-293, 2009.

[7] K. M. M. Aung and Y.-P. Ting, "Bioleaching of spent fluid catalytic cracking catalyst using Aspergillus niger," Journal of Biotechnology, vol. 116, no. 2, pp. 159-170, 2005. 
[8] A. Bharadwaj and Y.-P. Ting, "Bioleaching of spent hydrotreating catalyst by acidophilic thermophile Acidianus brierleyi: Leaching mechanism and effect of decoking," Bioresource Technology, vol. 130, pp. 673-680, 2013.

[9] D. Mishra, D.-J. Kim, D. Ralph, J.-G. Ahn and Y.-H. Rhee, "Bioleaching of metals from spent lithium ion secondary batteries using Acidithiobacillus ferrooxidans," Waste Management, vol. 28, no. 2, pp. 333-338, 2008.

[10] J. K. Magnuson and L. L. Lasure, "Organic Acid Production by Filamentous Fungi," in Advances in Fungal Biotechnology for Industry, Agriculture, and Medicine, Boston, MA, Springer, 2004, pp. 307-340. 